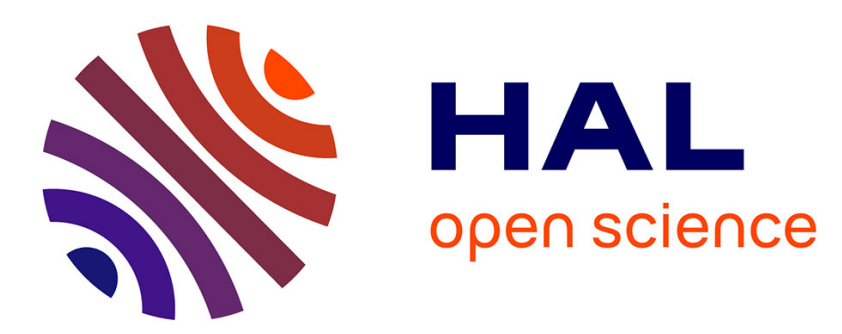

\title{
Microstructurally-based analysis and computational modeling of shock consolidation
}

S. Shang, D. Benson, M. Meyers

\section{To cite this version:}

S. Shang, D. Benson, M. Meyers. Microstructurally-based analysis and computational modeling of shock consolidation. Journal de Physique IV Proceedings, 1994, 04 (C8), pp.C8-521-C8-526. 10.1051/jp4:1994881 . jpa-00253442

HAL Id: jpa-00253442

https://hal.science/jpa-00253442

Submitted on 1 Jan 1994

HAL is a multi-disciplinary open access archive for the deposit and dissemination of scientific research documents, whether they are published or not. The documents may come from teaching and research institutions in France or abroad, or from public or private research centers.
L'archive ouverte pluridisciplinaire HAL, est destinée au dépôt et à la diffusion de documents scientifiques de niveau recherche, publiés ou non, émanant des établissements d'enseignement et de recherche français ou étrangers, des laboratoires publics ou privés. 


\title{
Microstructurally-based analysis and computational modeling of shock consolidation
}

\author{
S.S. Shang, D.J. Benson and M.A. Meyers \\ Department of Applied Mechanics and Engineering Sciences, University of California, San Diego, LaJolla, \\ California 92093-0411, U.S.A.
}

\begin{abstract}
Résumé: Les processus microstructuraux les plus importants dans la consolidation par ondes de choc sont identifiés et illustrés pour un alliage à base de nickel et une céramique (SiC). Les phénomènes suivants ont étés observés: vorticité, fusion des régions entre les poudres, et formation de vides. Plusieurs mécanismes de dissipation sont analisés: déformation plastique, frottement interparticulaire, énergie microcinétique, et création de défauts (dislocations et lacunes). Une équation analytique est developée pour l'énergie nécessaire pour consolider une poudre en fonction de la contrainte d'écoulement, taille de poudre, porosité, et température, pour une épaisseur donnée de la région de fusion sur la surface des poudres. Les résultats analytiques sont comparés aux solutions numériques obtenues au moyen de modélisation eulerienne par elements finis. Les limitations du compactage par ondes de choc sont presentées.
\end{abstract}

\begin{abstract}
The most important microstructural processes involved in shock consolidation are identified and illustrated for a nickel-based superalloy and silicon carbide. Interparticle melting, vorticity, voids, and particle fracture are observed. Various energy dissipation processes are identified and analyzed: plastic deformation, interparticle friction, microkinetic energy, defect generation. An analytical expression is proposed for the energy requirement to shock consolidate a powder as a function of strength, size, porosity, and temperature, based on a prescribed interparticle melting layer. These analytical results are compared to numerical solutions obtained by modeling the compaction of a discrete set of particles with an Eulerian finite element program. Based on the Analysis and computations, the inherent limitations of shock consolidation are identified and discussed.
\end{abstract}

\section{INTRODUCTION}

The shock consolidation of materials has been reviewed by a number of investigators: Gourdin [1], Prummer [2], Sawaoka [3]. Models that predict the pressure required for consolidation of "soft" materials, based exclusively on the melting of particle surfaces, have ben proposed by Gourdin [4] and Schwarz $e t$ al. [5]. For "hard" materials the plastic deformation requires a non-negligible energy, and models have been developed and applied to real materials by Nesterenko [6], Ferreira and Meyers [7], and Potter and Ahrens [8]. In this paper, the energetic aspects of shock consolidation will be discussed in simple analytical terms. The results of large-scale Eulerian computations using a two-dimensional geometry (cylindrical particles) will be presented. The results of analysis, computations, and observations point to intrinsic limitations of shock consolidation.

\section{Observation on Shock-Consolidated Materials}

The essential features of shock-consolidated materials are reviewed in order to be compared to the predictions of Section 3 and 4. The impact between particles, in metals, does not lead to a symmetric plastic deformation that would be predicted from a hydrostatic, quasistatic compression when the particle velocity is above a few hundreds of meters per second. The formation of jets, and the deformation of 

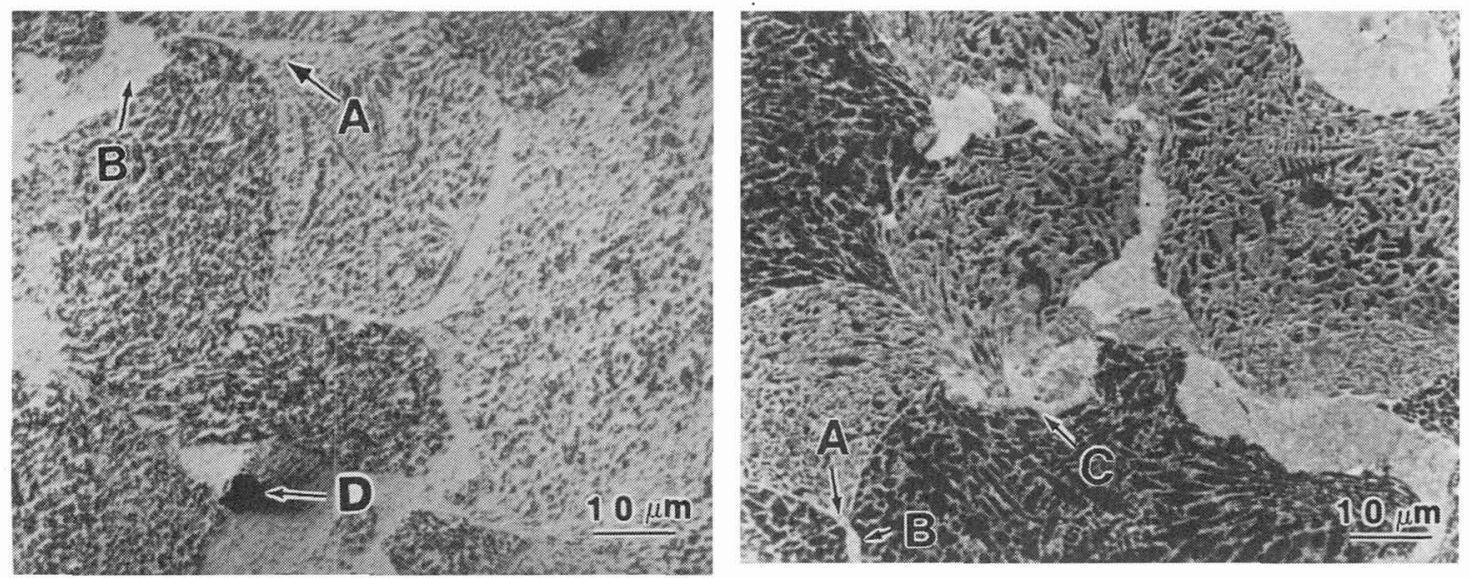

Figure 1. Optical micrographs of shock consolidated Inconel 718 powder; micrograph showing molten and resolidified regions (arrow A), particles deformed into a "parachute" shape (arrows B); evidence for vorticity (arrows C), and voids due to solidification shrinkage (arrows D).
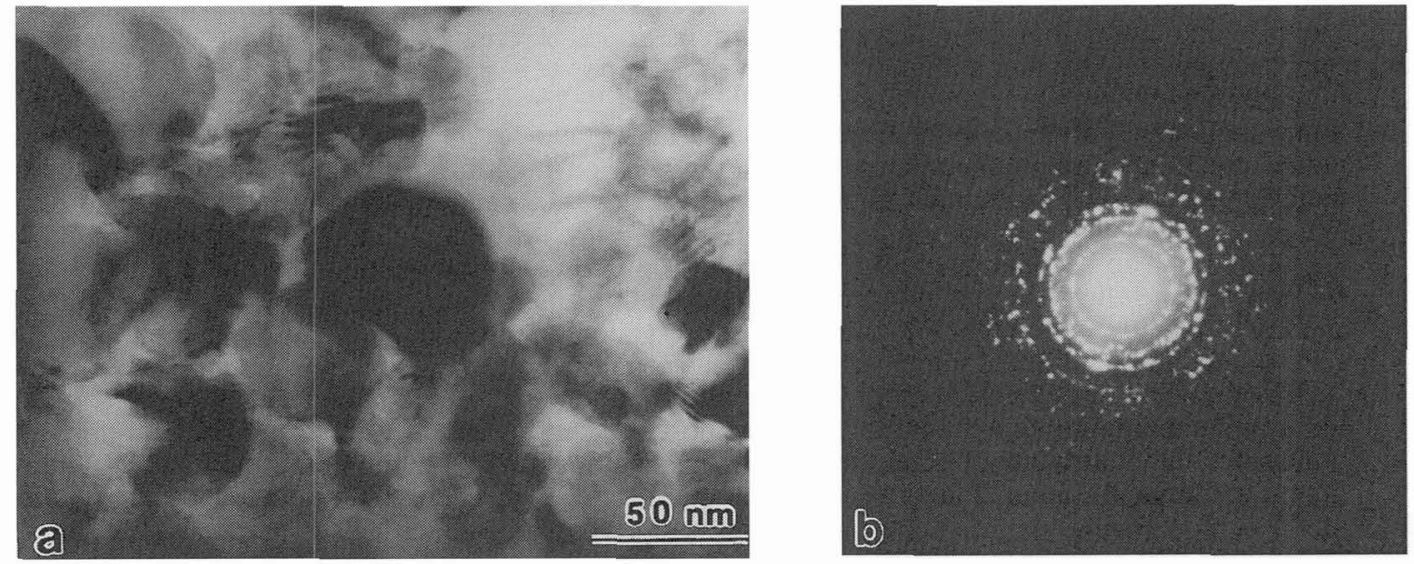

Figure 2. (a) Transmission electron micrograph and (b) electron diffraction pattern of molten/resolidified region in shock consolidated Inconel 718 powder.
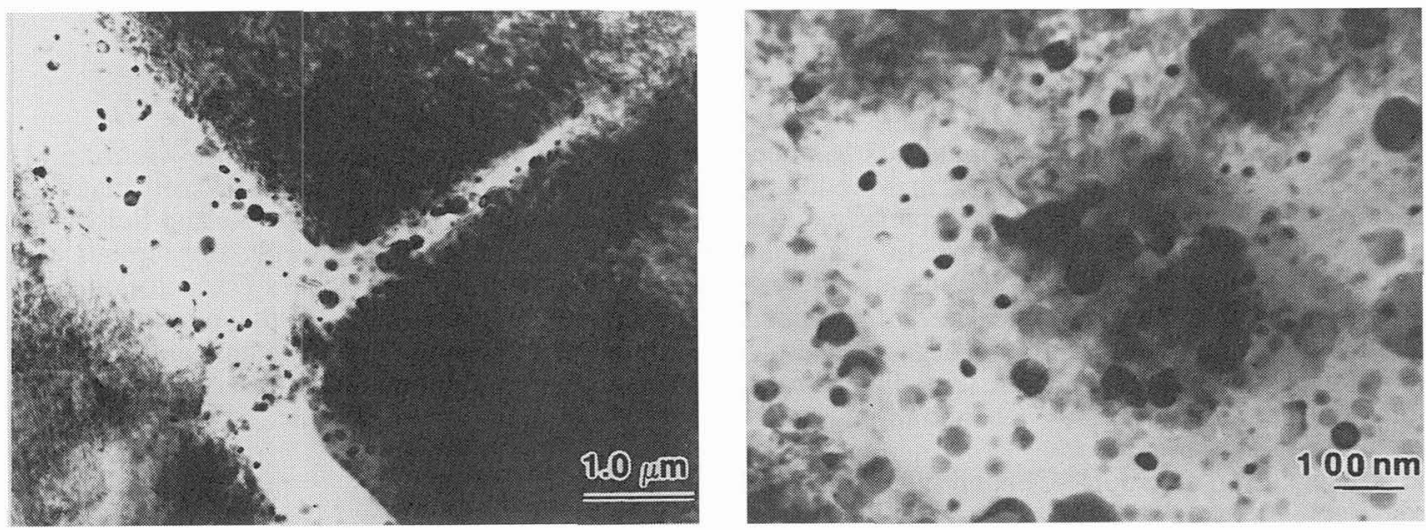

Figure 3. Transmission electron micrographs of shock consolidated $44 \mu \mathrm{m} \mathrm{SiC} \mathrm{showing} \mathrm{lattice} \mathrm{distortion}$ in the interior of $\mathrm{SiC}$ particle and interparticle regions. 
spherical particles into "parachutes" is shown by arrows A in Figure 1. This focused plastic deformation produced by shock waves has been observed by Gourdin [1] and predicted by Williamson and Berry[9]. The tips of these regions, in Figure 1, show evidence of melting (arrows B). The white areas formed from the dendritic structure of the particles are due to interparticle melting [10]. These clear regions are microcrystalline or nanocrystalline in structure, as illustrated by Figure 2, which shows grains with an approximate diameter of $0.1 \mu \mathrm{m}$ and the corresponding diffraction pattern. Evidence for vorticity, or redundant plastic deformation, is also presented in Figure 1, and is marked by arrows C. An additional feature shown in Figure 1(b) are two voids (marked by arrows D) that are produced by the shrinking associated with solidification of the interparticle melt regions. Similar features are reported by Ferreira et al. [11].

The behavior of shock-consolidated ceramics can be quite different. Although it is well known that ceramic particles can undergo plastic deformation under shock consolidated conditions and that interparticle melting contributes to bonding, there are reports of particle fracture and bonding without interparticle melting. Transmission electron microscopy inevitably reveals a high density of defects in shock-processed ceramics [12]. The interparticle melt regions are smaller than in the case of metals and it is even possible that these layers are often overlooked. Figure 3(a) shows the interface between three particles in shock-consolidted SiC. The clear region has a width of $\sim 1 \mu \mathrm{m}$, and spheroidal particles with a diameter of $1.20 \mathrm{~nm}$ are seen. These are crystallization centers inside an amorphous region. The cooling rate was so high that crystallization of the molten interparticle SiC layer was almost completely inhibited. A second, and very important feature of shock-consolidated ceramics is shown in Figure 4. Often, particles fracture under the effect of shock waves. The stresses set up within the particles are highly inhomogeneous, and existing flaws can be activated by tensile stresses due to, for instance, bending of the particles. It has been observed that larger particles tend to fracture whereas small particles preferentially undergo plastic deformation.

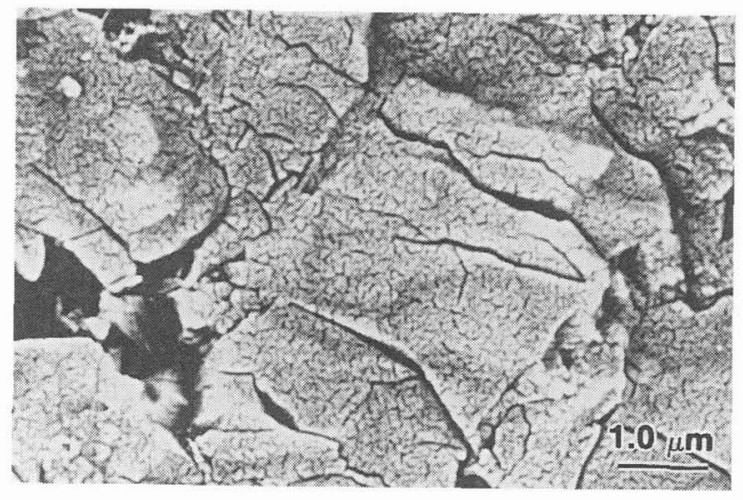

Figure 4. Particle fracture produced by shock consolidation of silicon carbide (initial particle size equal to $7 \mu \mathrm{m})$.

\section{ANALYTICAL COMPUTATION OF ENERGY REQUIREMENTS IN SHOCK CONSOLIDATION}

A number of complex phenomena occur during the passage of a shock wave through a powder. These phenomena can be, to a first approximation, subdivided into: (a) The material is plastically deformed; the collapse of the voids requires plastic flow. A plastic deformation energy has to be computed. (b) The plastic flow of the material is a dynamic process, leading to interparticle impact, friction, and plastic flow beyond the flow geometrically necessary to collapse the voids. We will call this component "microkinetic energy". The entire plastic deformation path is changed by virtue of the dynamics of the process. The kinetic energy acquired by the material elements being plastically deformed eventually dissipates into thermal energy. (c) Melting at interparticle regions: It is known that energy is preferentially deposited at the particle surface, leading eventually to their melting. This is the main component of Schwarz et al. [5]'s model. (d) Defect energy: Point, line, and interfacial defects are produced by the passage of the shock wave. (e) Friction energy: The rearrangement of the powders at the shock front requires relative motions, under the applied stress. Thus, friction may play a role in energy deposition at the shock front. (f) Fracture energy: Brittle materials may consolidate by fracturing. The comminuted particles can more efficiently fill the voids. (g) Gas compression: compaction is most often conducted with the powder being initially at atmospheric pressure. Thus, the gaps between the powders are filled with gas. Shock 
compaction of the powders compresses and heats these gases. This effect was considered first by Lotrich, Akashi, and Sawaoka [13]. (h) Shock initiated chemical reactions: Reactive elements or compounds can be added to the powders that are being consolidated. These exothermic reactions can be used to deposit additional energy at the powder surfaces, thereby assisting bonding. This approach was introduced by Akashi and Sawaoka [14].

The various energetic contributions can be computed, and this is described in greater detail by Shang $[15]$ and Meyers et al. $[3,16]$. The principal contributions are plastic deformation $\left(\mathrm{E}_{\mathrm{vc}}\right)$ the kinetic aspects of void collapse (microkinetic energy) $\left(\mathrm{E}_{\mathrm{k}}\right)$, and the frictional energy $\left(\mathrm{E}_{\mathrm{f}}\right)$. Developing expressions for these different contributions, and equating the shock energy to the dissipated energy:

$$
\frac{1}{2} P\left(\frac{1}{\rho_{f}}-\frac{1}{\rho_{o}}\right)=E_{v c}+E_{k}+E_{f}
$$

one arrives at the following equation:

$$
P=\frac{2 \rho_{0} \rho_{f}}{\left(\rho-\rho_{0}\right)}\left[\frac{1}{2} m\left(\frac{a_{0}-c}{t}\right)^{2}+\frac{0.1 P \xi Z \mu}{\rho}+\frac{2.97 Y_{y}}{1-\rho_{0}}\left(\frac{-\rho_{\mathrm{f}}^{2}-\rho_{0}^{2}}{2}+\rho_{\mathrm{f}} \rho_{\mathrm{g}}\right)\right]
$$

Where $\rho 0$ and $\rho_{f}$ are the densities, $Y_{y}$ the flow stress of the material, $m, a_{0}$, and $f$ are particle size parameters, $\mu$ is the friction coefficient, $Z$ the coordination number, and $\xi$ is the fraction of contact surface. Successive iterations are needed to arrive at $P$. The melting energy is a direct result of the plastic deformation, microkinetic, and friction energies. By considering a prescribed interparticle melting layer, it is possible to calculate the pressure required to consolidate a material as a funciton of initial density (distention) and particle size. This is shown in Figure 5 for Inconel 718 (a nickel-base superalloy), cubic boron nitride, and $\mathrm{SiC}$. A normalized plot of $\mathrm{P} / \mathrm{Y}$ versus distention was produced for different particle sizes. As the distention increases, the $\mathrm{P} / \mathrm{Y}$ ratio required for shock consolidation of a fixed particle size decreases. Conversely, as the particle size is decreased, the $\mathrm{P} / \mathrm{Y}$ ratio required increases. The differences between the different materials are due to the different material properties.

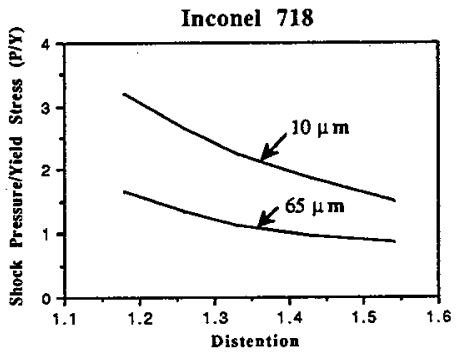

a

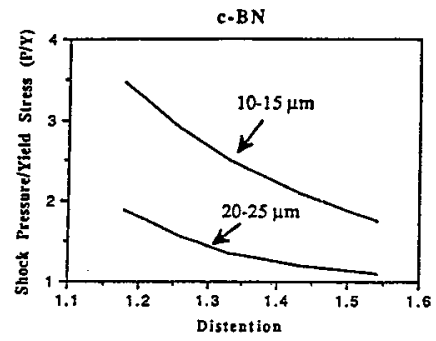

b

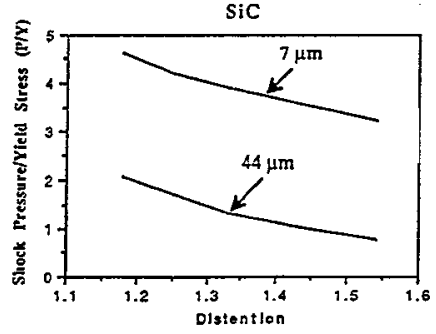

C

Figure 5. Shock pressure/yield stress vs distension for (a) Inconel 718, (b) c-BN, and (c) SiC at different particle sizes.

\section{DIRECT NUMERICAL SIMULATION OF SHOCK COMPACTION}

The complex deformation pattern occurring in shock consolidation is best captured by computational modeling. The simplifying assumptions in the simple analytical model presented in the previous section are very drastic and the physical processes are only brought out by numerical methods. Benson [17] presents an overview of explicit Lagrangian and Eulerian codes. A model boundary value problem was used to simulate the propagation of the shock wave through the powder. The tridimensional problem is reduced to two dimensions, and spherical particles (of varying diameters) are simulated as cylinders. The green density was taken as $80 \%$ of the theoretical density, and calculations were performed for the nickelbase superalloy and silicon carbide. The Steinberg-Guinan plasticity model [18] was used in combination with the Mie-Gruneisen equation of state. A particle size distribution was assumed based on experimental measurements. Figure 6(a) shows the original configuration of the powders, whereas the configurations after shock impact velocities of $0.25,1$, and $2 \mathrm{~km} / \mathrm{s}$ on Inconel 718 powder are shown in Figure $6(\mathrm{~b})$. At $0.25 \mathrm{~km} / \mathrm{s}$ the shock energy is sufficient to collapse all voids. As the impact velocity is increased, the "microkinetic" energy of the powders increases, and plastic deformation at the interfaces exceeds significantly the value needed for void collapse. Thus, one can separate this plastic deformation into a "geometrically necessary" component and a "redundant" component; the latter is due to the microkinetic 

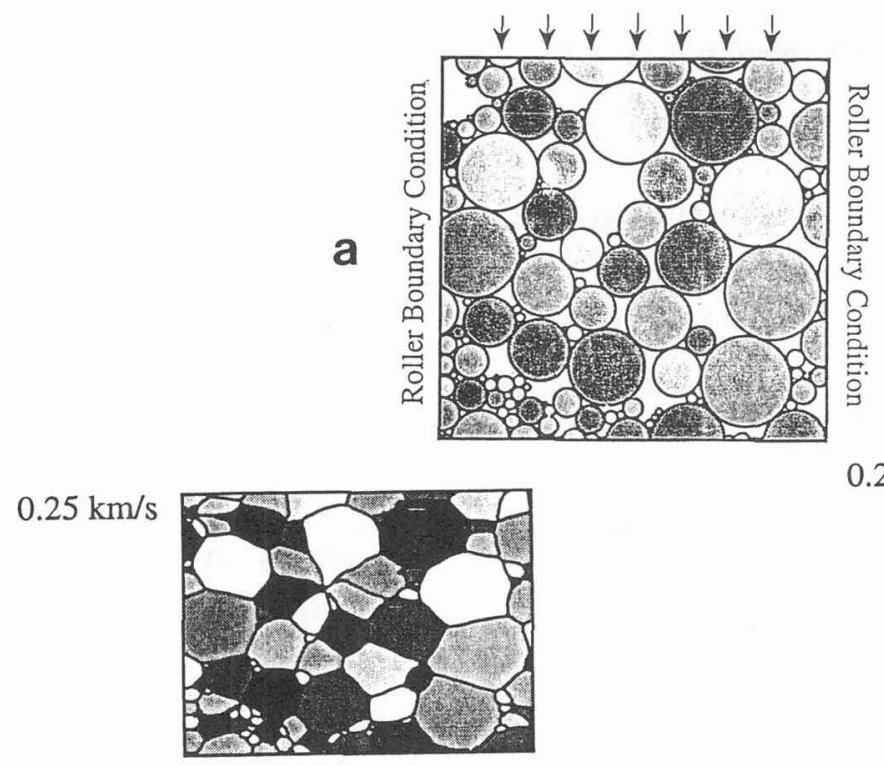

$0.25 \mathrm{~km} / \mathrm{s}$

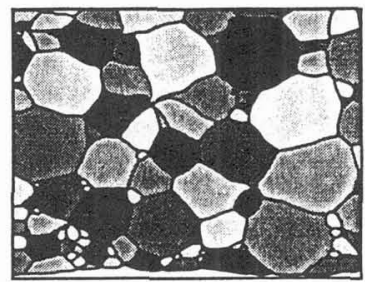

$1.00 \mathrm{~km} / \mathrm{s}$

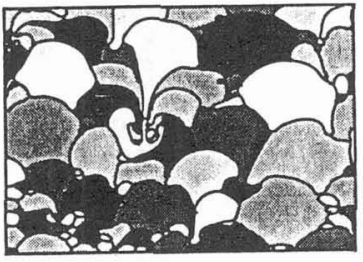

$1.00 \mathrm{~km} / \mathrm{s}$

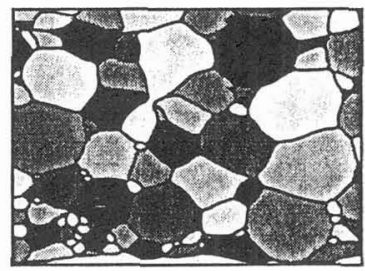

$2.00 \mathrm{~km} / \mathrm{s}$

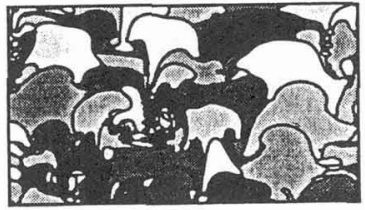

$2.00 \mathrm{~km} / \mathrm{s}$

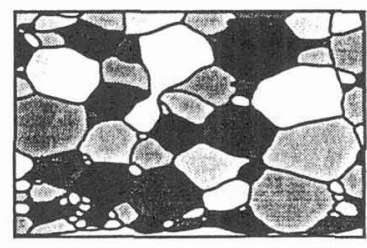

Figure 6(a). The model boundary value problem for cylindrical particles with an initial porosity of nineteen percent; (b) predictions for Inconel 718; (c) predictions for SiC.

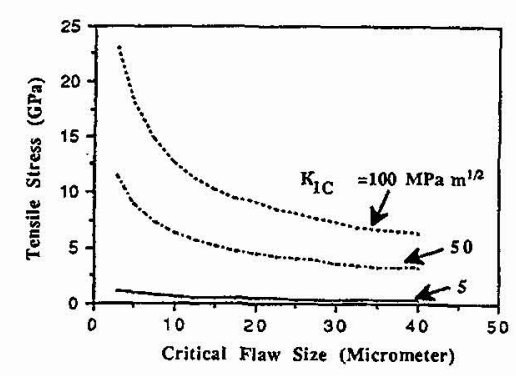

a

Figure 7. (a) Critical flaw size as a function of tensile stress for materials with different fracture toughnesses; (b) variation of critical tensile stress for 10 and $25 \mu \mathrm{m}$ flaw activation with shock stress required for consolidation: notice danger zone. 
energy and is responsible for the localized temperature spikes that lead to melting and bonding. The application of the same calculational procedure to silicon carbide yields results that are considerably different. This can be seen by comparing Figs. 6(b) and Figure 6(c). At $1 \mathrm{~km} / \mathrm{s}$, the shock energy is only sufficient to collapse the voids in SiC, whereas for the nickel-base superalloy a considerable amount of "redundant" plastic deformation takes place.

\section{LIMITATIONS OF SHOCK CONSOLIDATION PROCESS}

There exist two major problems in shock consolidation. One is cracking of the compacts at both the microscopic and macroscopic levels. The other is a lack of uniformity in microstructure and mechanical properties within the resulting compacts. Figure 7(a) shows plots of critical flaw size, a, as a function of tensile stress, $\sigma$ for materials having different fracture toughnesses, $K_{I C}$. These plots were made using the well known fracture mechanics equation: $\sigma=\mathrm{K}_{\mathrm{IC}} / \sqrt{\pi \mathrm{a}}$. It is difficult to conceive a shock consolidation process in which no flaws are left, and the particle size is a good indicator of the inherent flaw size in a shock consolidated material. The three fracture toughnesses given, 5,50 , and $100 \mathrm{MPa} \sqrt{\mathrm{m}}$, are characteristic of brittle (ceramics), tough (steel, titanium alloys) and very ductile materials (copper, nickel), respectively. Figure 7(b) shows the critical tensile stresses for $25 \mu \mathrm{m}$ and $10 \mu \mathrm{m}$ particle sizes as a function of the compressive stresses needed to consolidate the respective powders. The compressive stresses were taken from Ferreira and Meyers' calculation [7], at a distention corresponding to an initial density of $65 \%$ of the theoretical density (this is a typical value for powders). Tensile stresses due to reflections are always present in shock consolidation systems. In well designed systems a significant portion of the tensile stresses is trapped. When the tensile stresses exceed the critical tensile stresses for the specific material, failure occurs; this is shown in Figure 7(b) in a schematic fashion. A realistic line shows $\sigma_{\mathrm{t}}=0.1 \sigma_{\mathrm{c}}$, i.e., the tensile reflections have, at most, an amplitude of $10 \%$ of the compressive pulse.

Thus, a "Danger Zone" is marked in the figure. By reducing the shock amplitude point $[\mathrm{A}$ (corresponding to a hypothetical material) is changed to $\mathrm{B}$.

Three approaches can be implemented for improved shock consolidation: (a) Reduction of tensile stresses requires systems where the design geometry is optimized. (b) Shock energy can be reduced by thermal or chemical energy in an effort to improve compact quality. (c) The reduction in powder size reducing a, the flaw size, increases the safe consolidation zone. Thus, nanocrystalline ceramic powders should be more amenable to shock consolidation.

Acknowledgements This research was supported by the National Science Foundation Grant DMR 8713258 and DMR 91-5835R1 and by the Lawrence Livermore National Laboratory (IGPP).

\section{REFERENCES}

1. Gourdin, W. H., Progr. Mater. Sci. 30 (1986) 39.

2. Prümmer, R., Explosivverchichtung Pulvriger Substanzen, Springer-Verlag, Berlin, 1987.

3. Meyers, M. A., Shang, S. S., and Hokamoto, K., in "Shock Waves in Materials Science", ed. A.B. Sawaoka, Springer-Verlag, Tokyo, 1993, p. 145.

4. Gourdin, W. H., J. Appl. Phys., 55 (1984) 172.

5. Schwarz, R. B., Kasiraj, P. Vreeland, T., and Ahrens, T. J., Acta Met., 32 (1984) 1243.

6. Nesterenko, V.F., Proc. Novosibirsk Conference on Dynamic Compaction, Russia, (1988) p. 100.

7. Ferreira, A., and Meyers, M. A., in "Shock-Wave and High-Strain-Rate Phenomena in Matrerials", eds. M. A. Meyers, L. E. Murr, and K. P. Staudhammer, M. Dekker, NY, 1992, p. 361.

8. Ahrens, T. J., Bond, G. M., Yang, W., and Liu, G., Source cited in ref. 7, p. 339.

9. Williamson, R. L., and Berry, R. A., in "Shock Waves in Condensed Matter", ed. Y. Gupta, Plenum, NY, 1986, p. 341 .

10. Wang, S. L., Meyers, M. A., and Szecket, A., J. Matls, Sci. 23 (1988) 1786.

11. Ferreira, A., Meyers, M. A., and Thadhani, N. N., Met. Trans. 23A (1992) 3251.

12. Graham, R. A., Morosin, B., Venturini, E. L., and Carr, M. J., Ann. Rev. Mater. Sci. 16 (1986) 315.

13. Lotrich, V. F., Akashi, T., and Sawaoka, A. B., in "Metallurgical Applications of Shock Wave and High-Strain-Rate Phenomena", eds. L. E. Murr, K. P. Stanuhammer, and M. A. Meyers, M. Dekker, 1986 , p. 277.

14. Akashi, T., and Sawacka, A. B. US Patent 4, 655, 830 (1987).

15. Shang, S. S., "Production of Dense Silicon Carbide, Cubic Boron Nitride, Diamond, and Titanium Aluminide by Dynamic Processing and Hot Isostatic Pressing", Ph.D. Dissertation, UCSD, 1993.

16. Meyers, M. A., Benson, D. J., and Shang, S. S., "Shock Compression of Condensed Matter", 1992, in press.

17. Benson, D. J., Comp. Meth. in Appl. Mech. and Eng., 99, (1992) 235.

18. Steinberg, D. J., and Guinan, M. W. "A High Strain Rate Constitutive Model for Metals", Technical Report UCRL-80465, Lawrence Livermore National Laboratory, 1978. 